\title{
Changes in Policy and Endoscopic Procedures during the 2019 Coronavirus Disease Outbreak: A Single Center Experience
}

\author{
Adi Lahat and Avidan Benjamin \\ Department of Gastroenterology, Sheba Medical Center, Tel Hashomer, Sackler School of Medicine, Tel Aviv University, Tel Aviv, Israel
}

Background/Aims: The coronavirus disease-19 (COVID-19) pandemic forced endoscopy units to enact major changes on daily practice and policy. The Chaim Sheba Medical Center is a tertiary referral center located in the center of Israel, and serves cities with high infection rates. Our aim was to review the policies enacted during this outbreak and study their influence on the performance of endoscopic procedures.

Methods: Following the revision of work protocols, personnel were divided into two permanent and physically separate working groups and screening procedures were rescheduled. Relevant data including the number of endoscopic examinations, type of procedure performed, and patient referrals and indications were taken from a computerized database and evaluated. The study included data for January-March 2018-2020, and a comparison among the data from each year was performed.

Results: As of March 2020, the total number of endoscopic examinations performed reduced by $44 \%(p<0.0001)$ as compared to previous years, gastroscopy examinations reduced by $39 \%(p=0.02)$, and lower endoscopy procedures reduced by $57 \%(p<0.0001)$. Meanwhile, the number of advanced endoscopic procedures performed remained consistent with previous years. The indications for performance of gastroscopy and lower endoscopy were different in March 2020, while these remained unchanged for advanced endoscopic procedures.

Conclusions: The current policy appears to serve both our initial goals: protecting personnel and patients' safety and minimizing potential damage from delayed endoscopic procedures. A longer term follow-up study is needed in order to fully analyze our results. Clin Endosc 2021;54:48-54

Key Words: Colonoscopy; COVID-19 pandemic; Endoscopy; Gastroscopy; Policy

\section{INTRODUCTION}

Since the recognition of an outbreak of the new coronavirus called SARS-CoV-2 in Wuhan, China in December 2019, the infection has spread rapidly, with the World Health Organization declaring it to be a worldwide pandemic on March 11, $2020{ }^{2}$ The disease caused by the 2019 coronavirus is com-

Received: May 15, 2020 Revised: June 21, 2020

Accepted: July 21, 2020

Correspondence: Adi Lahat

Department of Gastroenterology, Sheba Medical Center, Tel Hashomer, Sackler School of Medicine, Tel Aviv University, P.O.B. 39040, Ramat Aviv, Tel Aviv 69978 Israel

Tel: +972-5-266-67501, Fax: +972-3-530-2060, E-mail: zokadi@gmail.com ORCID: https://orcid.org/0000-0003-1513-7280

cc This is an Open Access article distributed under the terms of the Creative Commons Attribution Non-Commercial License (http://creativecommons.org/ licenses/by-nc/3.0) which permits unrestricted non-commercial use, distribution, and reproduction in any medium, provided the original work is properly cited. monly referred to as coronavirus disease-19 (COVID-19). The virus is known to cause flu-like symptoms as fever, cough, weakness, and shortness of breath. ${ }^{3,4}$ Gastrointestinal (GI) symptoms such as diarrhea and vomiting were also reported in $10 \%-29 \%$ of patients in China, and up to $50 \%$ of patients in North America. ${ }^{5-7}$

Though human-to-human transmission occurs mainly through air droplets or direct contact, other pathways such as environmental contamination, fecal-oral transmission, and fomites were also identified. ${ }^{8,9}$ As a consequence of these transmission pathways, both upper and lower endoscopy are considered as high-risk procedures for both the endoscopist and the whole endoscopic team. Upper endoscopic procedures such as gastroscopies, endoscopic retrograde cholangiopancreatographies (ERCPs), and endoscopic ultrasounds (EUSs) expose the performing physician and endoscopy nurse to pulmonary and gastric secretions, while lower endoscopy 
procedures such as colonoscopies and transrectal ultrasounds may expose the team to fecal remnants containing unknown viral inoculum. ${ }^{10}$

Asymptomatic carriers were also shown to be a major source of infection, as they may unintentionally spread the virus to close contacts. ${ }^{11,12}$ Thus, there is a major risk of transmission not only in patients who were confirmed to be infected that must undergo endoscopic procedures with careful personnel protection, but also in those who are asymptomatic or whose results haven't been confirmed. Notably, infection risk in health care personnel was shown to be as high as $8 \%$ of all infected cases. ${ }^{13}$

Therefore, personnel protection and maximal separation among staff members during working hours is very important -both for personnel safety and to maintain the operational functions of the whole GI unit.

The infection rates rose rapidly among general population over the months of February-April 2020, with especially high outbreaks being noted in religious ultra-Orthodox Jewish communities. Our center, a tertiary referral hospital in the center of Israel, serves some cities with the largest religious ultra-Orthodox populations. Endoscopies are performed mainly on an ambulatory basis, with approximately $30 \%$ of procedures performed for screening purposes. Usually, between $30 \%-40 \%$ of endoscopic examinations are performed on hospitalized patients.

As a response to the COVID-19 outbreak, specific and dynamic regulations were published by the health ministry, with growing limitations on civilians' daily activities. State regulations regarding social distancing were gradually introduced in March 2020. In addition, specific recommendations for safe endoscopic practice were published. ${ }^{14-16}$ All these changes necessitated the rapid adaptation of local practice.

In the current study, our aim was to review the changes in decision-making and work practices in light of national and international recommendations, and to assess changes in the ambulatory and in-hospital numbers, types of procedures, and indications for endoscopies in our endoscopy centers as compared to the same time period in the past two years (2018-2019).

\section{MATERIALS AND METHODS}

Working procedures were restructured by local hospital management according to international and national recommendations. ${ }^{13-17}$ Accordingly, our protocols were formulated and approved by local infectious disease consultants and the hospital management.
Briefly, personnel were divided into two permanent working groups, with physical separation between these groups. While one group worked in endoscopy room, the other worked in the outpatients clinic.

In order to assess the new policy's effect on endoscopic procedures numbers and distributions, relevant data from our computerized database was collected and evaluated. Data extraction was performed using the hospital's specialized coded database, which contains a specific code for each endoscopic procedure performed. The database is completely anonymized.

Search words included: gastroscopy, colonoscopy, double balloon enteroscopy, sigmoidoscopy, EUS, ERCP, percutaneous endoscopic gastrostomy (PEG), Esophageal stent insertion, esophageal dilatation, EUS-guided pancreatic pseudocyst drainage.

Additional data extracted contained patient referrals (ambulatory versus hospitalized), indications for procedures and the total number of endoscopic examinations performed.

Data was collected for months January- March during the years 2018, 2019 and 2020 and a comparison between these years was performed.

\section{Statistical analysis}

All statistical analyses were performed using SPSS statistics ver. 25 (IBM Co., Armonk, NY, USA; 2015).

This is a descriptive study. The Chi Square test was used to compare the frequencies of different procedures performed during the first three months of 2020 and comparable months in 2018-2019. Two-sided $p$-values of less than 0.05 were considered statistically significant.

\section{RESULTS}

Our aims were to continue with routine work as much as possible in order to avoid delays in cancer diagnosis and management, and to avoid complications in relation to other non-malignant diseases such as inflammatory bowel disease and cirrhosis, and to maintain the security and health of both the personnel and patients.

Therefore, we divided the personnel into two independent groups which were separated physically from each other. Each group contained physicians including advanced endoscopists, nurses (including those highly skilled in advanced endoscopy), and administration personnel. Each group was able to function separately. All personnel were instructed not to arrive at work if they showed any symptoms of upper respiratory tract infection or fever. Furthermore, a daily health declaration form 
was filled by each stuff member, stating that they were healthy, asymptomatic, and that none of their household members had any symptoms.

For the purpose of patients' care in the outpatient clinic, the option of using telemedicine was offered individually to each patient.

Using telemedicine, the option to work from home was also applicable, and some staff members such as dietitians and psychologists could stay at home and still support the patients.

Special attention was given to personnel with high risk factors. Personnel above the age of 67 (the age of legal retirement) were given the option to stop working; one nurse chose that option while a senior physician chose to stop performing endoscopic procedures and to conduct their outpatient clinic from home via telemedicine. An advanced endoscopist who was more than 67 years old chose to continue performing endoscopic procedures. Staff members between 60-67 continued to work routinely.

Personnel protective equipment (PPE) was used according to local instructions and availability. At first, due to a shortage of highly protective masks (N95), endoscopic procedures were performed using surgical masks and a protective single use face shield. Single-use gowns and gloves were also used, just as they were in common practice. N95 masks were used when these became available. All other staff members used a surgical mask (one per day). In the beginning of April, the hospital received a donation of face shields made using $3 \mathrm{D}$ printers, increasing the protection of the staff.

Endoscopic training was not performed during these months. Academic consultations and literature reviews were performed using long-distance digital platforms such as the Zoom application).

Along with the rearrangement of personnel, changes were made to endoscopy procedures. First, all screening procedures were re-scheduled for later dates. All patients scheduled for elective procedures due to other indications were contacted by phone. Several of them chose not to go to the hospital and to reschedule their procedure to a later date. Patients who confirmed their arrival were rescheduled such that there were longer intervals in between the arrival of patients in order to avoid crowding in the endoscopy area. All symptomatic patients 40 years old or older were given the option to arrive as planned. Procedures for patients younger than 40 were rescheduled unless their symptoms were suggestive of malignant disease or benign disease necessitating immediate therapy, such as rectal bleeding, excessive weight loss, change in bowel habits, abnormal imaging, and severe abdominal pain.

No accompanying persons were allowed to enter the endoscopy unit. Patients were triaged according to their risk of infection with COVID-19. Patients from high-risk areas were instructed to undergo a COVID-19 polymerase chain reaction test 24 hours before arrival. All patients were instructed to wear masks upon arrival, and underwent temperature measurement at the entrance to the hospital. Patients with a body temperature of $38^{\circ} \mathrm{C}$ or more were not allowed into the hospital building.

The hospital policy regarding hospitalized patients did not change, and endoscopic procedures were performed as per indication. All patients suspected of COVID-19 infection were repeatedly tested for the presence of SARS-CoV-2 ribonucleic acid through an oropharyngeal swab test, as per the hospital's regulations. Patients infected with COVID-19 were isolated in special units, and endoscopic examinations were performed in those units using dedicated endoscopic equipment by an endoscopist and the assisting nurse who both wore complete PPE.

Endoscopy rooms were cleaned and disinfected after their use by each patient. This necessitated longer breaks between examinations. Endoscopes were cleaned as usual. One dedicated endoscopy unit was left at the specialized COVID-19 intensive care unit, and specifically served patients confined in this unit.

The effects of local state regulations, which began being published gradually in March 2020, and the hospital's current policy on the total number of endoscopic procedures performed during the COVID-19 outbreak can be seen when comparing the numbers from January-March 2020 to the total number of procedures done in the same months in the years 2018-2019.

Fig. 1. shows the total number of endoscopic examinations performed and patient referrals (ambulatory versus hospitalized) during the period of January-March 2020 compared to the same months in 2018 and 2019. While the total numbers did not differ significantly in January and February, the total number of endoscopic examinations performed in March 2020 reduced by $44 \%$ as compared to previous years. Meanwhile, for hospitalized patients, the number of endoscopic examinations performed reduced by $42 \%-55 \%$ (333 compared to 527 and 745 on 2018 and 2019, respectively), while those of ambulatory patients reduced by 39\%-44\% (924 compared to 1,514 and 1,638 on 2018 and 2019, respectively). The ratio of hospitalized/ambulatory examinations was 0.36 in March 2020, which did not change significantly from the ratio during previous months, which varied between $0.33-0.49$.

Fig. 2. shows the types of procedures performed during the months of January-March 2020 as compared to those performed during the same months in 2018 and 2019. While the number of procedures during January-February $2020 \mathrm{did}$ 


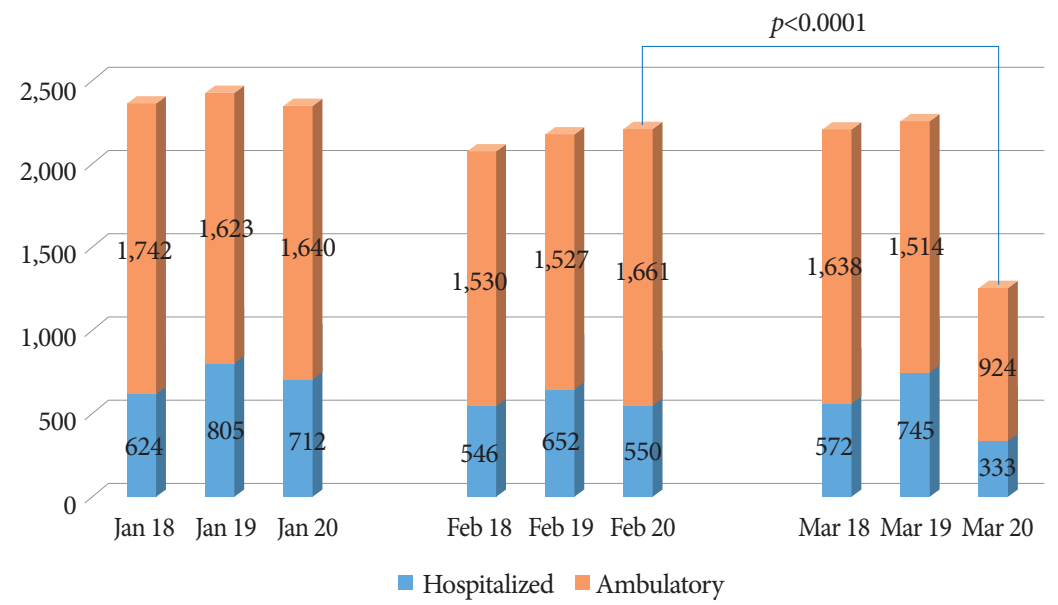

Fig. 1. Total number of endoscopic procedures performed from January-March (2018-2020).

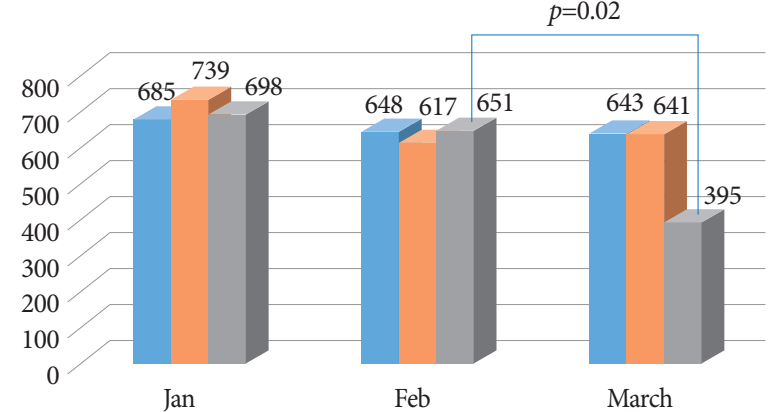

(A)

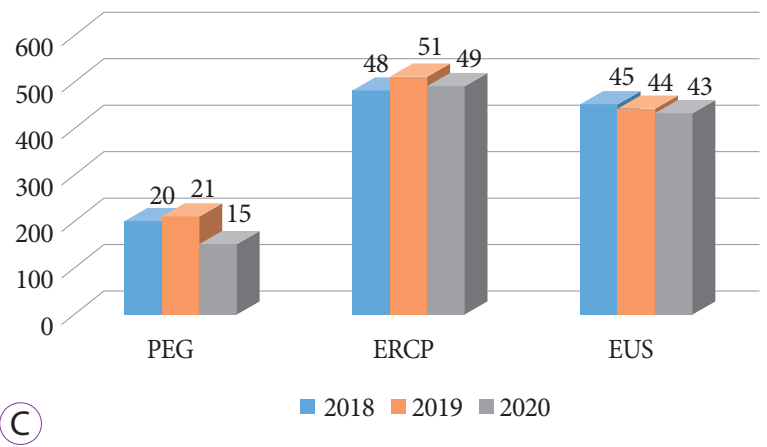

not differ much from that of previous years, gastroscopy examinations in March 2020 reduced by 39\% (395 as compared to 643 and 641 in 2018 and 2019) ( $p=0.02$ ) (Fig. 2A), while the frequency of lower endoscopy procedures (colonoscopy and sigmoidoscopy) were reduced by $52 \%-57 \%$ in 2020 (464

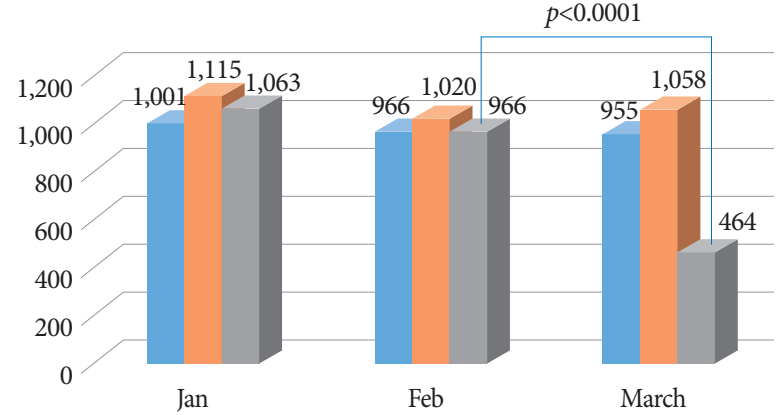

(B)

- $2018-2019 \square 2020$

Fig. 2. Total number of endoscopic procedures performed from JanuaryMarch (2018-2020). (A) Total number of gastroscopies performed from January-March (2018-2020). (B) Total number of lower endoscopy procedures performed from January-March (2018-2020). (C) Total number of advanced procedures performed from January-March (2018-2020). ERCP, endoscopic retrograde cholangiopancreatography; EUS, endoscopic ultrasound; PEG, percutaneous endoscopic gastrostomy.

as compared to 955 and 1,058 on 2018 and 2019, respectively $(p<0.0001)$ (Fig. 2B).

The most common advanced endoscopic procedures performed at this center are EUS, ERCP, and PEG. Other procedures are performed less frequently (less than 10 per month), 
Table 1. Indications for Gastroscopy in March 2020 Compared to Indications during February 2020

\begin{tabular}{lcc}
\hline Indication & $\begin{array}{c}\text { \% of examinations } \\
\text { during March } \\
\mathbf{2 0 2 0}\end{array}$ & $\begin{array}{c}\text { \% of examinations } \\
\text { during February } \\
\mathbf{2 0 2 0}\end{array}$ \\
\hline Epigastric pain & 34 & 25 \\
Upper GI bleeding & 25 & 10 \\
Anemia & 17 & 14 \\
Dysphagia/foreign body & 10 & 8 \\
\hline Suspected lesion on & 9 & 3 \\
imaging & 5 & 12 \\
Others (mainly weight & & 5 \\
loss) & - & 10 \\
\hline Dyspepsia & - & 5 \\
\hline Heartburn & - & 3 \\
\hline Peptic disease follow-up & - & 5 \\
\hline Vomiting & - & \\
\hline Therapeutic & & \\
\hline
\end{tabular}

GI, gastrointestinal.

thus, these were excluded from analysis. As shown in Fig. 2C, the frequencies of EUS and ERCP did not differ much from previous years, whereas the frequency of PEG procedures showed a very mild reduction on March 2020 compared to previous years ( 15 procedures done as compared to 20 and 21 on 2018 and 2019, respectively).

The indications for upper and lower endoscopy changed as well in March 2020. The list of indications for the examinations performed during March 2020 and their frequencies as compared to those performed during February 2020 as reference are shown in Table 1 for gastroscopy and Table 2 for colonoscopy. Similar indications seen in previous months were not shown in the tables. The indications for advanced endoscopic procedures did not change from previous years or months, thus these were not shown in a table. Furthermore, all ERCP and PEG examinations were performed for therapeutic purposes. EUS examinations were usually performed for the advanced evaluation of previously diagnosed lesions.

\section{DISCUSSION}

The global COVID-19 outbreak exposed health care systems worldwide to many significant challenges. Along with the obvious and recognized challenge of simultaneously treating multiple difficult patients, many of whom need mechanical
Table 2. Indications for Lower Gastrointestinal Endoscopy in March 2020 Compared to Indications in February 2020

\begin{tabular}{lcc}
\hline Indication & $\begin{array}{c}\text { \% of examinations } \\
\text { March 2020 }\end{array}$ & $\begin{array}{c}\text { \% of examinations } \\
\text { February 2020 }\end{array}$ \\
\hline $\begin{array}{l}\text { Rectal bleeding+ } \\
\text { occult blood loss }\end{array}$ & 17 & 15 \\
\hline $\begin{array}{l}\text { Anemia } \\
\text { Abnormal imaging }\end{array}$ & 8 & 8 \\
$\begin{array}{l}\text { Change in bowel } \\
\text { habits }\end{array}$ & 7 & 2 \\
\hline $\begin{array}{l}\text { IBD } \\
\text { Pain }\end{array}$ & 10 & 10 \\
\hline Polyp follow up & 10 & 10 \\
\hline $\begin{array}{l}\text { Screening+ family } \\
\text { history of CRC }\end{array}$ & 19 & 10 \\
\hline Others & 15 & 28 \\
\hline
\end{tabular}

CRC, colo-rectal cancer; IBD, inflammatory bowel disease.

ventilation, the need to protect health care providers in the face of the very high infective capacity of the virus became one of the most urgent requirements. Data from Italy showed up to a $20 \%$ infectious rate among healthcare personnel, and healthcare providers composed $8 \%$ of the total infected population. ${ }^{18,19}$ In Wuhan, China, the source of the virus, healthcare workers were three times more likely to be infected than the general population. ${ }^{20}$ Since the recognition of the problem, many recommendations and guidelines were published in order to minimize healthcare risks of infection and enhance the protection of healthcare workers. ${ }^{18-26}$

Specific attention was given to high-risk procedures, in which the operating personnel are exposed to the patients' aerosol. All endoscopic procedures involving the upper GI (gastroscopy, EUS, ERCP) are therefore considered as highrisk. Evidence revealing viral excretion in stool and the possibility of fecal-oral viral transmission marked lower endoscopic procedures as potentially high-risk procedures as well. ${ }^{8-10} \mathrm{Con}$ sidering these risks, several guidelines and recommendations for endoscopic practice during COVID-19 outbreak were issued, ${ }^{14-17,27,28}$ and several manuscripts describing local experiences in operating endoscopic units during the viral outbreak were published. ${ }^{29}$

The Chaim Sheba Medical Center is the largest medical center in Israel, located in the center of the country, and was the first hospital to receive COVID-19 infected patients in Israel. 
Overall, there were more than 350 hospitalized COVID-19 patients in the hospital. Our Gastroenterology department serves as a tertiary referral center for some of the most COVID-19 infected cities in Israel. Furthermore, the endoscopy unit is the largest in Israel and serves both hospitalized and ambulatory patients. During the current COVID-19 outbreak, we tried to focus on two major goals: first, the personnel and patients' safety, and second, maintaining the maximal capacity of routine work in order to avoid late cancer diagnosis and potential complications. Therefore, our working plan included strict physical separation between two working groups, donning full PPE depending on availability, a deliberate reduction in endoscopic procedures performed through postponing screening procedures while performing procedures when indicated, and using telemedicine when technically feasible. Meanwhile, personnel protection and distancing seem to be effective, with no symptoms of infection among staff members.

As shown in Fig. 1, during March 2020, our total endoscopic procedures performed dropped by $44 \%$ as compared to March 2018 and 2019. The reduction in endoscopic examinations occurred similarly in hospitalized and ambulatory patients, and the ratio of hospitalized/ambulatory patients was relatively stable compared to the previous years. These findings first reflect the reduction in ambulatory patients; both due to our department policy of rescheduling screening procedures and due to the patient's preference to postpone elective examinations, and second, the total reduction in hospitalized patients due to the hospital's policy to postpone elective surgeries and the patient's preference to not visit the hospital unless absolutely urgent.

Data analysis of the frequency of specific types of endoscopic procedures indicates that the highest reduction was approximately $55 \%$ in lower endoscopic procedures, while there was a milder reduction in gastroscopies (40\%), and there was no reduction in the frequency of advanced endoscopic procedures (Fig. 2A-C). These finding may be clarified by looking at gastroscopy and lower endoscopy indications (Tables 1 and 2). As shown in Table 2, the main indication for lower GI endoscopy in routine scheduling is screening (almost $30 \%$ of examinations). In March 2020, as a consequence of our policy, only $15 \%$ of procedures were performed for screening purposes. Other indications did not differ significantly.

Since there is no screening program for gastric cancer in Israel (due to the relatively low prevalence), there was no deliberate decrease in gastroscopies performed. However, as seen in Table 1, patients suffering from mild symptoms as dyspepsia or heartburn chose to postpone their examination, while patients suffering from more severe symptoms (pain, anemia) and patients with urgent indications (bleeding) chose to undergo the examination as scheduled. The amount of advanced endoscopic procedures was left unchanged since the indica- tions for these procedures were highly robust.

Our study had a few limitations. First, as the COVID-19 situation is still developing, a long-term evaluation is needed in order to assess our policies' effectivity. Furthermore, due to the paucity of COVID-19 diagnostic tests (tests are only performed when there are symptoms), we were unable to assess the number of asymptomatic infected personnel members. Another limitation is our study design as a descriptive single center experience. Data from different centers may be completely different according to their local policy and regulations.

In conclusion, in our current study, we reviewed our policy during COVID-19 outbreak in light of national and international guidelines and studied its influence on endoscopic procedures performed and on current personnel protection. We believe our current policy serves both our initial goals: protecting the personnel and patients' safety, as well as minimizing potential damage caused by delaying endoscopic procedures. A longer term follow-up study is necessary in order to fully analyze and verify our findings.

Conflicts of Interest

The authors have no potential conflicts of interest.

Funding

None.

Author Contributions

Conceptualization: Adi Lahat, Avidan Benjamin

Data curation: $\mathrm{AL}, \mathrm{AB}$

Formal analysis: $\mathrm{AL}, \mathrm{AB}$

Investigation: $\mathrm{AL}, \mathrm{AB}$

Methodology: $\mathrm{AL}, \mathrm{AB}$

Resources: $\mathrm{AL}, \mathrm{AB}$

Validation: $\mathrm{AL}, \mathrm{AB}$

Writing-original draft: $\mathrm{AL}, \mathrm{AB}$

$\begin{array}{ll}\text { ORCID } & \\ \text { Adi Lahat: } & \text { https://orcid.org/0000-0003-1513-7280 } \\ \text { Avidan Benjamin: } & \text { https://orcid.org/0000-0001-9397-1372 }\end{array}$

\section{REFERENCES}

1. World Health Organization. Pneumonia of unknown cause - China [Internet]. Geneva: WHO; c2020 [updated 2020 Jan 5]. Available from: https://www.who.int/csr/don/05-january-2020-pneumonia-of-unkowncause-china/en/.

2. World Health Organization. WHO Director-General's opening remarks at the media briefing on COVID-19 - 11 March 2020 [Internet]. Geneva: WHO; c2020 [updated 2020 Mar 11]. Available from: https://www.who. $\mathrm{int} / \mathrm{dg} /$ speeches/detail/who-director-general-s-opening-remarks-at-themedia-briefing-on-covid-19---11-march-2020.

3. National Health Commission of the People's Republic of China. Diagnosis and treatment of new coronavirus pneumonia (version 5) [Internet]. Beijing: National Health Commission of the People's Republic of China; 
c2020 [updated 2020 Jan 30]. Available from: http://www.nhc.gov.cn/.

4. Chan JF, Yuan S, Kok KH, et al. A familial cluster of pneumonia associated with the 2019 novel coronavirus indicating person-to-person transmission: a study of a family cluster. Lancet 2020;395:514-523.

5. Guan WJ, Ni ZY, Hu Y, et al. Clinical characteristics of coronavirus disease 2019 in China. N Engl J Med 2020;382:1708-1720.

6. Hajifathalian K, Mahadev S, Schwartz RE, et al. SARS-COV-2 infection (coronavirus disease 2019) for the gastrointestinal consultant. World J Gastroenterol 2020;26:1546-1553.

7. Patel KP, Patel PA, Vunnam RR, et al. Gastrointestinal, hepatobiliary, and pancreatic manifestations of COVID-19. J Clin Virol 2020;128:104386.

8. Li Q, Guan X, Wu P, et al. Early transmission dynamics in Wuhan, China, of novel coronavirus-infected pneumonia. N Engl J Med 2020;382:1199-1207.

9. Yeo C, Kaushal S, Yeo D. Enteric involvement of coronaviruses: is faecal-oral transmission of SARS-CoV-2 possible? Lancet Gastroenterol Hepatol 2020;5:335-337.

10. Johnston ER, Habib-Bein N, Dueker JM, et al. Risk of bacterial exposure to the endoscopist's face during endoscopy. Gastrointest Endosc 2019;89:818-824.

11. Bai Y, Yao L, Wei T, et al. Presumed asymptomatic carrier transmission of COVID-19. JAMA 2020;323:1406-1407.

12. Rothe C, Schunk M, Sothmann P, et al. Transmission of 2019-nCoV infection from an asymptomatic contact in Germany. N Engl J Med 2020;382:970-971.

13. Davies G, Natanson P. Italy reports nearly 6,000 new cases of coronavirus and more than 600 deaths in the past 24 hours [Internet]. New York (NY): ABC News; c2020 [updated 2020 Mar 20]. Available from: https:// abcnews.go.com/International/italy-coronavirus-death-toll-surpasses-china-task-force/story?id=69704673.

14. Repici A, Maselli R, Colombo M, et al. Coronavirus (COVID-19) outbreak: what the department of endoscopy should know. Gastrointest Endosc 2020;92:192-197.

15. Chiu PWY, Ng SC, Inoue $\mathrm{H}$, et al. Practice of endoscopy during COVID-19 pandemic: position statements of the Asian Pacific Society for Digestive Endoscopy (APSDE-COVID statements). Gut 2020;69:991-996.

16. Lui RN, Wong SH, Sánchez-Luna SA, et al. Overview of guidance for endoscopy during the coronavirus disease 2019 pandemic. J Gastroenterol Hepatol 2020;35:749-759.

17. The Israeli Gastroenterological Association (IGA) recommendations. Recommendations for endoscopic procedures during COVID-19 outbreak [Internet]. Zerifin: Israeli Gastroenterology Association; c2020 [updated $2020 \mathrm{Mar}$. Available from: https://gastro.doctorsonly. co.il/2020/03/187342.

18. The Lancet. COVID-19: protecting health-care workers. Lancet
2020;395:922.

19. Paterlini M. On the front lines of coronavirus: the Italian response to covid-19. BMJ 2020;368:m1065.

20. Huh S. How to train health personnel to protect themselves from SARS$\mathrm{CoV}-2$ (novel coronavirus) infection when caring for a patient or suspected case. J Educ Eval Health Prof 2020;17:10.

21. Centers for Disease Control and Prevention. Interim infection prevention and control recommendations for patients with suspected or confirmed coronavirus disease 2019 (COVID-19) in healthcare settings [Internet]. Atlanta (GA): CDC; c2020 [updated 2020 Mar 23]. Available from: https://www.simlaweb.it/wp-content/uploads/2020/03/ Infection-Control-Severe-acute-respiratory-syndrome-coronavirus-2-SARS-CoV-2-CDC.pdf.

22. Communicable Diseases Network Australia. CDNA national guidelines for the prevention, control and public health management of COVID-19 outbreaks in residential care facilities in Australia [Internet]. Canberra: CDNA; c2020 [updated Jul 29]. Available from: https://www.health.gov. $\mathrm{au} /$ sites/default/files/documents/2020/03/coronavirus-covid-19-guidelines-for-outbreaks-in-residentialcare-facilities.pdf.

23. European Centre for Disease Prevention and Control. Infection prevention and control and preparedness for COVID-19 in healthcare settings - fourth update [Internet]. Stockholm: ECDC; c2020 [updated 2020 Jul 3]. Available from: https://www.ecdc.europa.eu/en/publications-data/ infection-prevention-and-control-and-preparedness-covid-19-healthcare-settings.

24. Canada.ca. Coronavirus disease (COVID-19): for health professionals [Internet]. Ottawa: Government of Canada; c2020 [updated 2020 Aug 18]. Available from: https://www.canada.ca/en/public-health/services/ diseases/2019-novel-coronavirus-infection/health-professionals.html.

25. Health Protection Scotland. COVID-19 - guidance for health protection teams (HPTs) [Internet]. Glasgow: Health Protection Scotland; c2020 [updated 2020 Aug 20]. Available from: https://www.hps.scot.nhs.uk/ web-resources-container/covid-19-guidance-for-health-protectionteams-hpts/.

26. Adams JG, Walls RM. Supporting the health care workforce during the COVID-19 global epidemic. JAMA 2020;323:1439-1440

27. Ong J, Cross GB, Dan YY. Prevention of nosocomial SARS-CoV-2 transmission in endoscopy: international recommendations and the need for a gold standard. Gut 2020;69:1145-1148.

28. Sociedad Española de Patología Digestiva; Asociación Española de Gastroenterología. Recommendations by the SEPD and AEG, both in general and on the operation of gastrointestinal endoscopy and gastroenterology units, concerning the current SARS-CoV-2 pandemic (March, 18). Rev Esp Enferm Dig 2020;112:319-322.

29. Han J, Kim EY. Sharing our experience of operating an endoscopy unit in the midst of a COVID-19 outbreak. Clin Endosc 2020;53:243-245. 